\title{
Developing a Registry of Healthcare-Associated Infections at Intensive Care Units in West China: Study Rationale and Patient Characteristics [Corrigendum]
}

\author{
Wang W, Zhu S, He Q et al. Clin Epidemiol. \\ 2019;11:1035-1045.
}

The authors advised that there was a mistake in the affiliation list that was overlooked during the revision process. The correct author and affiliation list should read as follows:

\author{
Wen Wang ${ }^{1, *}$ \\ Shichao Zhu ${ }^{2}$,* \\ Qiao $\mathrm{He}^{\mathrm{I}}$ \\ Rui Zhang ${ }^{3}$ \\ Yan Kang ${ }^{4}$ \\ Mingqi Wang' \\ Kang Zou' \\ Zhiyong Zong ${ }^{2,5}$ \\ Xin Sun'
}

'Chinese Evidence-Based Medicine Center and CREAT Group, West China Hospital, Sichuan University, Chengdu 61004I, People's Republic of China; ${ }^{2}$ Department of Infection Control, West China Hospital of Sichuan University, Chengdu, People's Republic of China; ${ }^{3}$ Information Center, West China Hospital, Sichuan University, Chengdu, People's Republic of China; ${ }^{4}$ Intensive Care Unit, West China Hospital of Sichuan University, Chengdu, People's Republic of China; ${ }^{5}$ Center of Infection Diseases, West China Hospital of Sichuan University, Chengdu, People's Republic of China

*These authors contributed equally to this work

\section{Publish your work in this journal}

Clinical Epidemiology is an international, peer-reviewed, open access, online journal focusing on disease and drug epidemiology, identification of risk factors and screening procedures to develop optimal preventative initiatives and programs. Specific topics include: diagnosis, prognosis, treatment, screening, prevention, risk factor modification,

systematic reviews, risk \& safety of medical interventions, epidemiology \& biostatistical methods, and evaluation of guidelines, translational medicine, health policies \& economic evaluations. The manuscript management system is completely online and includes a very quick and fair peer-review system, which is all easy to use. 